\title{
La trascendencia del Liberalismo doceañista en España y en América
}

\section{Maria Betlem Castellà I Pujols}

\section{Q OpenEdition \\ 1 Journals}

Édition électronique

URL : https://journals.openedition.org/ahrf/1757

DOI : 10.4000/ahrf.1757

ISSN : 1952-403X

Éditeur :

Armand Colin, Société des études robespierristes

Édition imprimée

Date de publication : 1 juin 2004

Pagination : 247-249

ISSN : 0003-4436

Référence électronique

Maria Betlem Castellà I Pujols, « La trascendencia del Liberalismo doceañista en España y en

América ", Annales historiques de la Révolution française [En ligne], 336 | avril-juin 2004, mis en ligne le

20 février 2006, consulté le 23 avril 2022. URL : http://journals.openedition.org/ahrf/1757 ; DOI :

https://doi.org/10.4000/ahrf.1757

Ce document a été généré automatiquement le 23 avril 2022.

Tous droits réservés 


\title{
La trascendencia del Liberalismo doceañista en España y en América
}

\author{
Maria Betlem Castellà I Pujols
}

\section{RÉFÉRENCE}

Manuel Chust et Ivana Frasquet (éd.), La trascendencia del Liberalismo doceañista en España y en América, Valencia, Biblioteca Valenciana, Col. Historia, Estudios, 2004, 231 p., ISBN 84-482-3680-7, $10 €$.

1 Avant que certains pragmatiques ne plongent dans le bicentenaire de la Révolution libérale espagnole, en écrivant n'importe quoi sur le premier libéralisme en Espagne ou sur la Constitution de Cadix, et, peut-être, avant que le bicentenaire de la Révolution libérale espagnole ne devienne - tout comme le bicentenaire de la Révolution française en Espagne - le forum de certains opportunistes, Manuel Chust et Ivana Frasquet, de l'Université Jaume I de Castellon, sont parvenus à regrouper dans un ouvrage intéressant et suggestif les derniers travaux d'une dizaine d'historiens qui consacrent actuellement la plupart de leurs recherches aux origines du libéralisme.

2 Après le vingt-cinquième anniversaire de la Constitution de 1978 et la remémoration que cet anniversaire suppose de la «Pepa»-la première constitution libérale espagnole, celle de 1812- paraît aujourd'hui, aussi attirant que nécessaire, ce recueil de dix articles, bien conçus, consacrés tant à la genèse qu'aux répercussions en Amérique de la Constitution de 1812. Tout le monde sait que pendant les anniversaires et les commémorations le nombre de publications augmente de façon parfois inégale, parfois inversement proportionnelle, à la qualité des travaux présentés.

3 Le mérite de ce recueil, présenté par Manuel Chust et Ivana Frasquet, s'appuie sur deux points: il montre les nouveaux axes de recherche sur le sujet «les origines du libéralisme en Espagne et en Amérique», et il offre au lecteur les nouvelles interprétations et les derniers résultats des recherches menées en Espagne et en 
Amérique sur ce sujet: libéralisme et répercussions de la Constitution libérale espagnole de 1812 au-delà de l'Espagne.

4 Ainsi, on peut apprécier, en lisant les articles présentés, que les nouveaux axes de recherche des historiens espagnols et américains qui travaillent sur la Révolution libérale espagnole et ses répercussions sont presque égaux à ceux de certains historiens français et américains qui consacrent, aujourd'hui, leurs recherches à la Révolution française. On parle, donc, et bien évidemment, des axes de recherches qui s'appuient actuellement sur le sujet: les colonies et l'histoire des femmes ou, si l'on préfère, l'histoire de genre.

5 Par ce type de travaux, ceux qui n'avaient jamais eu de voix dans l'historiographie l'obtiennent aujourd'hui. Autrement dit, ceux qui étaient restés invisibles recouvrent aujourd'hui leur visibilité. Manuel Chust et Ivana Frasquet ont fait entendre la voix et ont rendu visibles ceux que l'historiographie espagnole avait jusqu'aux années quatrevingt du dernier siècle jeté presque dans l'oubli : les Américains (députés, insurgés, criollos et indigènes) et les femmes.

6 Alors, mis à part le très intéressant article du professeur Lluís Roura qui insiste sur les ruptures incarnées par la Constitution libérale espagnole dans une analyse brève mais palpitante de la Constitution de 1812; ou le suggestif article du professeur Emilio La Parra sur la bonne image de Ferdinand VII, face à Godoy dans une première époque et à Napoléon Ier dans une deuxième; ou l'article attractif d'Antonio Rivera consacré au concept de liberté à l'époque des Cortès de Cadix, on se retrouve avec six articles très liés aux Américains et à leurs propos (ceux de Manuel Chust, José Luis Villacañas, Raymond Buve, Ivana Frasquet, Juan Ortiz et José Antonio Serrano), et un aux femmes (celui d'Anna Aguado).

7 Sept articles, donc, qui par le fait même de rendre visibles ceux qui jamais n'avaient été visibles renversent - si on les met en relation au contenu des trois articles déjà mentionnés - le regard maintenu presque jusqu'à aujourd'hui sur la genèse de la Constitution libérale espagnole, et, surtout sur le premier libéralisme.

De fait, on verra, à la lecture du recueil, que le regard sur certaines questions a bien changé. Surtout en lisant les articles où la parole et les agissements des Américains planent sur les travaux présentés. Le changement de perception s'explique par un renversement de fond en comble de certaines discussions qui jusqu'à maintenant avaient pour sujet: centralisme versus fédéralisme, nationalisme espagnol versus « nationalismes " périphériques ou autonomie versus indépendance.

Jusqu'à nos jours, les analyses de ces questions se regardaient majoritairement vis-à-vis des sympathies que certains députés de l'ancien royaume d'Aragon avaient de leurs constitutions, abolies par droit de conquête par Philippe $\mathrm{V}$ après avoir gagné la guerre. Par conséquent, ce qu'il y a de nouveau à la lecture du recueil ici présenté, c'est que l'analyse de ces questions prend en compte, à côté des sympathies décentralisatrices du Levant péninsulaire, les revendications américaines, autonomistes et fédéralistes.

10 Ainsi, en lisant cet ouvrage, on peut remarquer que les projets fédéralistes présentés à l'époque sont appréciés par les Américains et quelquefois les Américains eux-mêmes sont auteurs de projets fédéralistes. On peut apercevoir que certaines revendications autonomistes proviennent d'outre-mer. Et ainsi, on peut noter qu'à côté du nationalisme espagnol, il y a un nationalisme américain, disposé à l'indépendance et plus responsable peut-être que les sympathies décentralisatrices de certains députés de 
l'ancien royaume d'Aragon, des attitudes centralistes de certains députés des Cortès de Cadix.

11 Mais, certainement, l'apport de cet ouvrage n'est pas seulement le nouveau regard concernant certains débats qui ont rempli la plupart des ouvrages consacrés au libéralisme de Cadix pendant quelques décennies. La nouveauté de ce livre, c'est la tendance qu'il a à travailler les répercussions de la Constitution libérale espagnole dans les possessions coloniales de Ferdinand VII. Cela est vraiment intéressant, même si les travaux présentés dans ce recueil offrent seulement les répercussions de cette Constitution libérale dans le territoire de la Nouvelle Espagne (actuel Mexique) et pas dans ceux de la Nouvelle Granada, Pérou, La Plata ou Chili.

Néanmoins, avant d'achever ce compte rendu d'un ouvrage qui jusqu'ici n'a pas reçu que de bonnes critiques, il faut dire que, comme dans tout travail, il y a des points discutables. Mais il faut souligner, aussi, que ces points contestables sont seulement attribuables à certains articles. Ainsi, ce qui frappe d'abord en lisant certains articles, c'est l'analyse qu'on a encore aujourd'hui de la Révolution libérale espagnole comme une révolution bourgeoise (Manuel Chust et Anna Aguado); ou bien qu'on considère que les droits les plus authentiques du libéralisme sont la liberté et la propriété (Antonio Rivera) en oubliant qu'il y avait au XVIIIe siècle un autre courant de pensée libéral non-économiste - qui était pour le droit à l'existence et contre la liberté illimitée et la considération de la propriété comme un droit naturel.

13 À mon avis, l'origine de ces questions problématiques, qui n'enlèvent rien à la qualité globale de l'ouvrage, vient de ce qu'on observe malheureusement encore les processus libéraux par leurs résultats finaux. Il faut vraiment s'éloigner de cette pratique qui simplifie, obscurcit et fausse les résultats de recherches qui partent de points de vue absolument nouveaux. 